\title{
Caracterización de las tiendas de barrio de Cartagena
}

\author{
DELIMIRA GAITÁN, ING, MSc (C) \\ Universidad Nacional de Colombia/ Universidad de Cartagena \\ delimiragaitan@gmail.com.co
}

Ingeniera industrial de la Universidad Tecnológica de Bolívar y MSc en Administración.

\section{Resumen}

La presente investigación fue realizada en las tiendas de barrio de Cartagena, departamento de Bolívar en Colombia, cuyo propósito fue su caracterización, principales comportamientos y estrategias de defensa frente al desarrollo de otros canales de distribución, en especial los super e hiper mercados.

Para su desarrollo, se trabajó con información primaria, mediante la realización de entrevistas estructuradas en los diferentes establecimientos y la observación directa de las actividades que allí mismo se hacen. Así mismo el estudio está sustentado por información secundaria, en documentos de trabajos de investigaciones previas y propias, en las que se muestra la evolución de este segmento del comercio minorista.

\section{Palabras Claves}

Caracterización, canal de distribución, canasta familiar, consumidores, economía familiar, fidelidad, hiper mercados, menudeo, tenderos, tiendas de barrio.

\section{Abstract}

This research was conducted in stores of the City District of Cartagena, Bolivar department in Colombia, whose purpose was the characterization, their behaviors and their main defense strategies against the development of other distribution channels in particular the super and hyper markets.

For its development, we worked with primary information, conducting structured interviews in the different establishments and direct observation of the activities taking place within them. On the other hand the study is supported by secondary information on documents of previous research work and his own research which shows the evolution of this segment of retail in the city of Cartagena.

\section{Key words}

Characterization, distribution channel, market basket, consumers, family finances, faithfulness, hyper markets, retail grocers, convenience stores.
Fecha de recepción: 16 de junio de 2010 Fecha de aprobación: 07 de julio de 2010

\section{Introducción}

Cartagena, es la capital de Bolívar, y el eje del desarrollo económico, político, cultural y comercial a escala departamental. Localizada en el norte de Colombia, tiene una población de 1.015.616 habitantes, constituida para efectos administrativos en diez comunas conformadas por 190 barrios de diferentes estratos (DANE, 2009).

Las tiendas de barrio se han convertido en el motor de desarrollo de muchas zonas, en especial porque solucionan problemas de la demanda (mejores precios y ajuste de cantidades) a las familias y de la oferta, y a los tenderos como una alternativa efectiva de generación de empleo. De acuerdo con A.C. Nielsen (2001), mediante el canal tradicional o tiendas se realiza el 56,9\% de las ventas del sector minorista, así mismo, O' Byrne y Calp (2008, p. 4) afirma que el bajo nivel de ingresos y la dispersión de la población obligan al consumidor a comprar artículos en presentaciones pequeñas que suponen un desembolso menor y en el lugar más próximo.

Una de las fortalezas que presenta el pequeño comerciante en especial el de la ciudad de Cartagena frente a los grandes minoristas, es la función social que cumple, pues el trato personalizado le permite establecer relaciones más amistosas y agradables para la clientela; en un estudio sobre mercados minoristas tradicionales (Fernández, 1998a, p. 45) concluyó que aunque se incremente la cuota de mercado de las grandes superficies, las visitas frecuentes al 
pequeño comercio próximo pueden crear un vínculo más estrecho entre el comerciante o dependiente y el comprador.

Para (Fernández, 1998b, p. 46) una de las mayores oportunidades que muestran los tenderos es la flexibilidad, la cual les permite reaccionar rápidamente a los cambios producidos en los consumidores, los precios o las presentaciones de sus productos. Un tendero conoce a sus clientes, sabe cuáles son sus intereses y gustos. Además la cercanía de la mayoría de las tiendas de barrio ofrece comodidad para sus consumidores, sumado a un servicio amable, un buen surtido y facilidades de crédito.

Hoy la tienda de barrio en Cartagena ha ganado un espacio importante en el sector de comercio al detalle y es considerada como un canal complementario, por cuanto gran parte de los consumidores acude a estos puntos de venta, bien sea para reponer los artículos que se les acabaron en su compra en el supermercado o para realizar la mayoría de sus compras en aprovechamiento del crédito otorgado; además para un sector importante de la población constituye el único canal para poder acceder a hacer sus compras.

Así mismo (Fernández, 1998 p. 49) sostiene que tradicionalmente las personas han realizado sus compras en las plazas de mercado; el arraigo cultural que esto trae consigo permite a los pequeños autoservicios seguir cumpliendo con esta función social, pues el contacto personalizado también posibilita al comerciante establecer relaciones más amistosas y agradables para la clientela. Aunque se incremente la cuota de mercado de las grandes superficies, las visitas frecuentes al pequeño comercio próximo pueden crear una vinculación más estrecha entre el comerciante o dependiente y el comprador, lo que posibilita el logro de los dos fenómenos que caracterizan la filosofía del marketing actual: el desarrollo y mantenimiento de relaciones a largo plazo, más que la búsqueda de ventas puntuales, y la comunicación interactiva entre comprador y consumidor, que hace posible una adaptación rápida a los intereses cada vez más individualizados de los compradores.

La tienda forma parte de la cotidianidad de una buena porción de la población que habita en zonas residenciales, sobre todo de clases media y baja. En estos contextos la tienda es, además de expendio de productos, lugar de encuentro e interacción entre las personas que habitan su área de influencia, de la cual ella es un referente central. En este sentido, la tienda cumple una función social y cultural crucial e ineludible en el momento de estudiar las prácticas cotidianas de la población, como lo expresan Pérgolis y Moreno (1998, p. 12):

Los súper e hipermercados, los almacenes en cadena, no pueden reemplazar este espacio que, como lugar de enculentro, de transacción, de reconocimiento, se fortalece en los sectores más popullares de la ciudad.

\section{Pregunta de investigación}

¿Cuáles son las características de las tiendas de barrio de Cartagena (Bolívar), en Colombia?

\section{Metodología de investigación}

Para el desarrollo de la presente investigación, se trabajó con información primaria, mediante la realización de entrevistas estructuradas en los diferentes establecimientos y la observación directa de las actividades que allí se adelantan. Por otro lado, el estudio también está sustentado por información secundaria, en documentos de trabajos de investigaciones previas y en investigaciones propias desarrolladas sobre esta temática, en el que se muestra la distribución de productos de gran consumo y la evolución de este segmento del comercio minorista en Cartagena.

Por tal motivo se eligió una muestra aleatoria de 316 establecimientos de diferentes estratos socioeconómicos ubicados en diferentes barrios de la ciudad, entre ellos Mi vaquita, Los chagualos 1, 2 y 3, La creciente, Siglo XXI, Las bandas y Precios bajos, entre otros, los cuales se encuentran registrados en la Cámara de Comercio de la ciudad.

\section{Caracterización de las tiendas}

La Federación Nacional de Comerciantes (Fenalco, 2002), en Colombia, define los comercios tradicionales como aquellos desarrollados por un grupo familiar donde se comercializan productos de la canasta familiar y artículos de primera necesidad que funcionan en áreas de menos de $50 \mathrm{~m}^{2}$; la administración es 
informal ya que sus propietarios poseen un bajo perfil de formación académica; funcionan además bajo parámetros de una administración intuitiva y sin ningún o escaso registro de sus operaciones comerciales. Al incluir la variable libre servicio, separa en esta categoría a los denominados autoservicios; sin embargo, la gran mayoría de negocios registrados en Cámara de Comercio como autoservicios, por las demás características, son igualmente tiendas tradicionales.

Las tiendas de barrio presentan ventajas para el consumidor y el proveedor como se observa en la tabla 1 .

Tabla 1. Ventajas de la tienda de barrio

\begin{tabular}{|l|l|}
\hline \multicolumn{1}{|l}{$\begin{array}{l}\text { Ventajas para el } \\
\text { comprador }\end{array}$} & \multicolumn{1}{l|}{$\begin{array}{l}\text { Ventajas para el } \\
\text { proveedor }\end{array}$} \\
\hline $\begin{array}{l}\text { Cercanía que favorece la } \\
\text { inmediatez de la compra }\end{array}$ & $\begin{array}{l}\text { Sitio de reunión o punto de } \\
\text { encuentro }\end{array}$ \\
\hline $\begin{array}{l}\text { Crédito o préstamos } \\
\text { avalados solo en la } \\
\text { confianza }\end{array}$ & $\begin{array}{l}\text { Poder de negociación } \\
\text { centrado en el proveedor }\end{array}$ \\
\hline $\begin{array}{l}\text { Oferta de cantidades y } \\
\text { productos a la medida } \\
\text { de las necesidades y } \\
\text { capacidad de pago del } \\
\text { cliente }\end{array}$ & $\begin{array}{l}\text { Reducción de costos, en } \\
\text { términos de mercaderistas, } \\
\text { premios, codificación de } \\
\text { productos, tiempo de pago, } \\
\text { primer vestido, etcétera }\end{array}$ \\
\hline Servicio a domicilio & Ventas de contado \\
\hline Servicios adicionales & No hay devoluciones \\
\hline $\begin{array}{l}\text { Reconocimiento de la } \\
\text { persona como cliente }\end{array}$ & $\begin{array}{l}\text { Nicho de mercado que } \\
\text { permite la nivelación de } \\
\text { los puntos que se pierden } \\
\text { en la negociación con los } \\
\text { grandes supermercados }\end{array}$ \\
\hline $\begin{array}{l}\text { Horario especial: quince } \\
\text { horas diarias continuas }\end{array}$ & $\begin{array}{l}\text { Aumento de la demanda en } \\
\text { las tiendas de barrio }\end{array}$ \\
\hline Trato personalizado & $\begin{array}{l}\text { Confianza del consumidor } \\
\text { en el tendero }\end{array}$ \\
\hline pes
\end{tabular}

Fuente: elaboración propia, con base en investigación exploratoria.

En un estudio sobre hábitos, determinantes y características Porto y Herrera (2002) afirman que si bien el desarrollo del comercio minorista iniciado a mediados de la década de 1990, condujo al cierre de muchos comercios tradicionales de productos de gran consumo, a diferencia de otros países de la región, el efecto negativo se ha reversado principalmente en lo referente a las tiendas de barrio. En el país, comercio moderno y tradicional coexisten y crecen paralelamente con ventaja del segundo sobre el primero. Paradójicamente, la competencia horizontal, más que entre supermercados e hipermercados, ocurre entre estos y el comercio tradicional representado por las tiendas de barrio, que constituyen el mayor y más fuerte competidor de los grandes supermercados.

Para Londoño (2008, p. 67), aunque es manifiesto el poder del gran comercio sobre sus proveedores, muchos de ellos se han volcado a atender directamente al segmento de tenderos, que representa el $62 \%$ del mercado de productos de gran consumo. Debido a este interés particular en dichas dinámicas, se propuso realizar la presente investigación.

\section{Resultados}

La caracterización de la tienda de barrio en Cartagena se definió a partir del resultado de esta investigación, la cual permitió establecer características claves entre las que se pueden destacar: ubicación geográfica, dimensiones del local, formas de financiación, horarios de atención, nivel académico de los empleados, tecnología utilizada, tipo de servicio y perfil de los clientes, entre otros.

El servicio es personalizado, el cual de manera similar que en las tiendas de barrio no pierde la función social que cumplen, pues esta relación permite establecer alianzas más amistosas y agradables para la clientela; precios competitivos similares a los de los grandes supermercados operan en locales arrendados aproximadamente de entre 100 y $200 \mathrm{~m}^{2}$, según lo evidencia la encuesta. Los empleados tienen poca preparación académica, y no poseen tecnología alguna, con excepción de Mi vaquita, tienda que ofrece servicio de pago con tarjeta debito o crédito y sus productos están debidamente codificados, e incluso tienen un software para la sistematización y control de sus inventarios.

\section{- Rasgos positivos observados}

- Existencia de una alta motivación de mejora entre las empresas analizadas, aunque en ocasiones no se tiene claro cómo perfeccionar el desarrollo de sus negocios

- Elevado dominio del oficio y conocimiento de las características de los productos

- Alto grado de atención personalizada y excelente trato a los clientes. 


\section{- Perfil de los clientes}

- Residen a menos de cinco minutos de distancia

- Realizan compras dos o tres veces por semana

- Alrededor del 90\% de los establecimientos estudiados son de carácter familiar, donde trabajan al menos dos miembros de la familia.

También se destacan aspectos menos favorables como:

- Escasa gestión empresarial

- Escasa tecnología

- Descuidada imagen e identidad corporativa

- Falta definición de estrategias de diferenciación con respecto a la competencia

- Diversificación de la oferta poco justificada

- Economía familiar conjunta con el negocio y planteamientos no empresariales respecto al negocio, sino como forma de vida.

Tradicionalmente las personas de ingresos bajos han hecho sus compras en las tiendas de barrio -y continúan haciéndolo-, pese a que los precios unitarios sean superiores a los establecidos en supermercados y autoservicios. La tienda ofrece ventajas que no ofrece el supermercado, como:

- Cercanía: dependiendo del estrato socioeconómico del barrio puede disponer de una a cinco en su cuadra o a lo sumo caminar tres cuadras.

- Cantidades acordes con sus necesidades: se encuentran los productos en las cantidades (unidades y fracciones) que necesitan, acordes con la disponibilidad del dinero; puesto que el aumento en los índices de desempleo, ha llevado a gran parte de la población a vivir de lo que se denomina la actividad de "el rebusque". Esto significa que las personas, salen en busca del dinero para comprar lo que se va a consumir hoy (anexo 1), como por ejemplo: café y leche en polvo por cucharadas, media barra de jabón, una tacita o copita de aceite, etcétera.

- Trato personalizado: un tendero atiende en promedio cincuenta hogares; lo que le permite interactuar más con sus clientes y poder entrar en el detalle de sus necesidades y deseos, principalmente en lo referente al suministro de aquellos productos que no son de venta masiva, pero que algunas personas los consumen.

- Crédito (credicarton): cuenta con dos modalidades: el fiado y el dinero virtual sin intereses y teniendo como garantía solamente el voto de confianza, la palabra de cumplimiento.

- Horario extendido: normalmente inician labores a las 6 de la mañana y cierran entre 10 y 11 de la noche, y también atienden de domingo a domingo durante todo el año.

De igual manera se analizó el comportamiento de los hábitos de consumo de los habitantes de la ciudad por estratos y se obtuvieron los siguientes resultados:

En la población de la ciudad perteneciente al estrato uno, predomina para los subgrupos de la canasta familiar la tienda como principal lugar de compra de los mismos; lo anterior obedece a las características de trabajo de esta parte de la población, pues al recibir un sueldo diario (entre 1 y 5 dólares en promedio), les resulta muy costoso transportarse diariamente hacia diferentes lugares de compra, para adquirir las cantidades requeridas para un día. El consumo es diario y se utilizan medidas no convencionales, de menor cantidad (Gráfico 1, nexo A). Así mismo tienen mayores facilidades para acceder al crédito en este tipo de establecimientos.

En el estrato dos, se destaca que la tienda de barrio sigue siendo el establecimiento donde se realizan la mayoría de las compras, pero no hay que dejar de lado

Gráfico 1. Medidas más utilizadas para vender cantidades mínimas de productos en la tienda

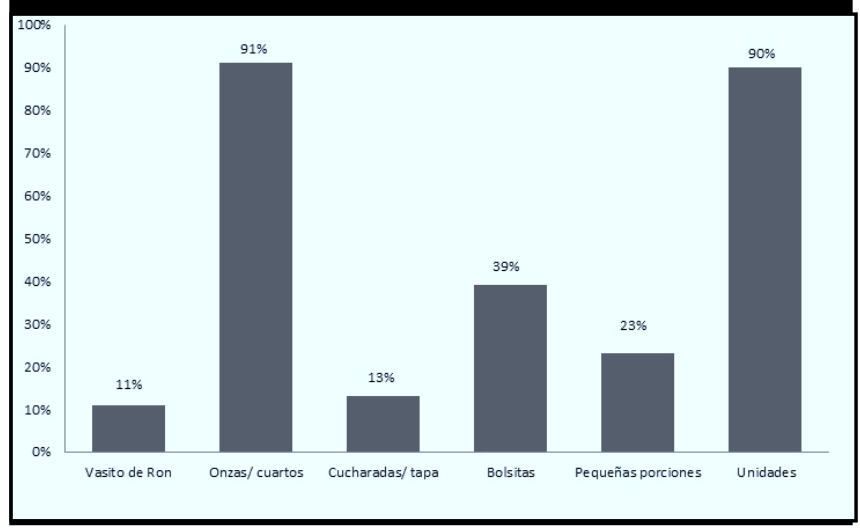

Fuente: encuesta. Base: 316. 
la importancia que alcanza la plaza de mercado de la ciudad (Bazurto), y aunque no predominan para todos los subgrupos de la canasta familiar sí logra hacerlo para algunos de ellos como: verduras, frutas y abarrotes, lo cual no quiere decir que por cada producto de estos últimos subgrupos la plaza de mercado, sea el principal centro de compra, con excepción de los abarrotes.

El estrato tres se caracteriza por ser el más heterogéneo de los analizados, al poseer no una sino varias características sobresalientes. La mejor posición económica de la familia de este estrato determina que el lugar de compra preferido por las mismas sea en este caso el supermercado de cadena, a este le sigue Bazurto pero, sin embargo, las tiendas no dejan de tener importancia.

Al igual que lo sucedido en el estrato tres, en el estrato cuatro la mayoría de las compras son realizadas en los supermercados de cadena y en la plaza de mercado de la ciudad, sin embargo este último obtiene una participación inferior con respecto al estrato tres, lo que permite inferir que el supermercado de cadena está ganando terreno y, a su vez, el supermercado de barrio también lo hace ya que se encuentra en tercer lugar en reemplazo de las tiendas.

El hecho de que el supermercado de cadena esté ganando participación con respecto a los demás lugares es una conciencia del mayor ingreso del estrato, puesto que conlleva a que se busquen plazas donde se adquieran productos con mayor comodidad y de mayor calidad, prueba de esto es que alimentos que en el estrato tres eran comprados en la plaza de mercados de la ciudad, como las verduras en el estrato cuatro, se compran en el supermercado de cadena.

Para Alvarado y Enríquez (2000), en su investigación sobre "Hábitos y motivos de compra de alimentos de las familias de estratos cinco y seis de Cartagena", encontraron que los habitantes de los estratos cinco y seis, el supermercado de cadena es el lugar de compra preferido, y en segundo lugar los supermercados de barrio, relegan a un tercer lugar la plaza de mercado de la ciudad, e n este caso Bazurto.

Finalmente, se puede observar que hay una influencia de los factores sociodemográficos, económicos y sicológicos en las decisión de la escogencia del sitio de compra de los habitantes de la ciudad, lo que obedece a los hábitos y costumbres de la población estudiada; hay que tener en cuenta que los estratos uno y dos agrupan gran parte de los hogares cartageneros, aproximadamente el 56\% del total de hogares de la ciudad.

\section{Características del tendero}

Entre algunas características generales del tendero se pueden nombrar: nivel de escolaridad, origen, edad, estado civil, conocimiento de su clientela, atención al público, ambientación otorgada al negocio, estrategias que utiliza para la ubicación de los productos y cortesía. A partir de estas características se analiza el factor socioeconómico a partir de los siguientes indicadores.

\section{Escolaridad}

En lo referente al nivel de escolaridad presentado en la población objeto de estudio en Cartagena, se tiene que $44 \%$ está en el nivel de bachillerato, $40 \%$ en el de primaria y $16 \%$ repartido por partes iguales entre niveles tecnológico y profesional (Gráfico 2); este resultado indica que el tendero se caracteriza por ser una persona de bajo nivel educativo.

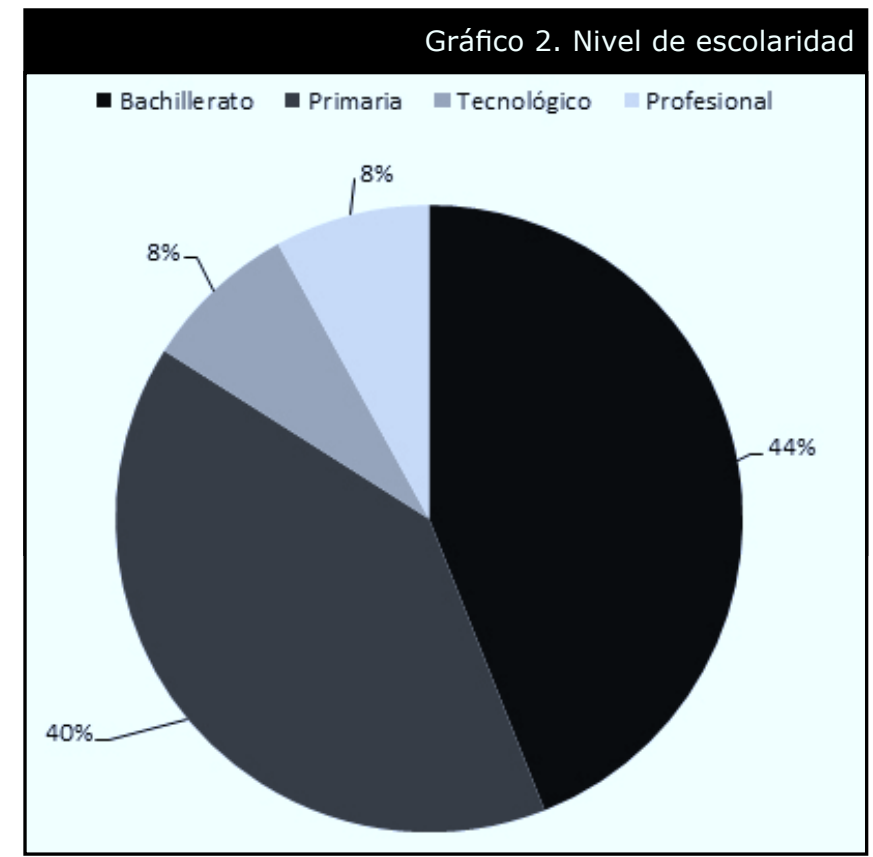

Este resultado no se aleja de la realidad nacional, por que al hacer la comparación con el estudio realizado por Fenalco (Gráfico 3) permite ver que la diferencia más relevante es de 9 puntos en el nivel primaria, en tanto los otros niveles muestran una diferencia no muy significativa, encontrándose casi en el mismo nivel que muestra Fenalco en su investigación. 


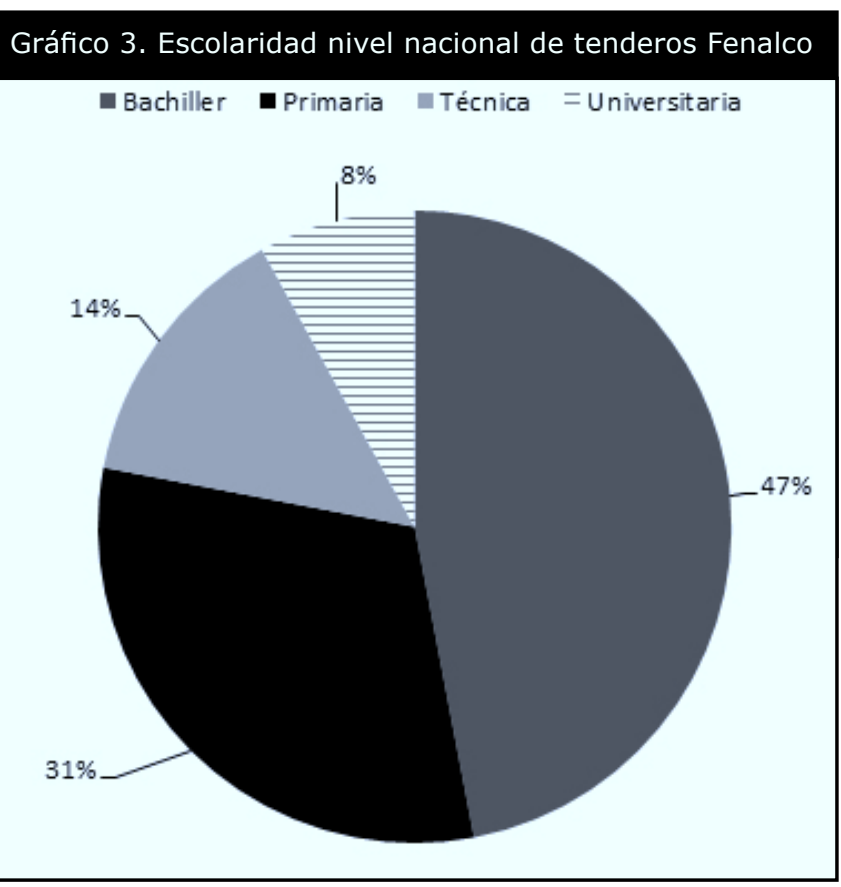

En un estudio sobre organización informal en el sector popular, Yudes (1990, p. 37), manifiesta que si bien las tiendas suelen responder a ciertas regulaciones legales y tributarias, atendiendo a su estructura interna y modo de funcionamiento estas pueden ser incluidas en el sector informal, pues en general cumplen con las características que lo distinguen, a saber: bajo nivel de capital, tecnología rudimentaria, relaciones laborales inestables, mano de obra familiar, duras condiciones de trabajo, carencia de asistencia y servicios sociales, y pobreza generalizada de la población dependiente de tales labores.

Para Yudes (1990, p. 41) este cuadro puede resultar un tanto dramático y no coincide con numerosos casos de tiendas muy prósperas, en general, esa es la norma, confirmada por datos como los reportados por la Revista Dinero, en su edición del 24 de junio de 2003: "En 1996 el tendero trabajaba con un margen del 40\% y ahora lo hace máximo con el 15\%”.

La vinculación de mano de obra no calificada o de difícil acceso al mercado laboral formal, hace de la tienda un eficaz dique al desempleo, y una forma de supervivencia para muchas personas que sumaban al principio de la década, según datos reportados por Areiza (2001, p. 82), investigador del Icesi, la impresionante cifra de más de un millón de empleados directos de tiendas de barrio.

\section{Composición por edad, sexo y procedencia del tendero}

De acuerdo con la investigación, se pudo constatar que en su mayoría, los tenderos de Cartagena son del interior del país en un $80 \%$, y más específicamente de Antioquia y Santander, la Costa en un $11 \%$ y, en especial, Cartagena en un $8 \%$ y, además, son tiendas que tienen entre dos y cinco años de funcionamiento; la edad del tendero oscila entre 28 y 45 años, debido a que no es común ver a una persona menor de 28 años dedicada a administrar este tipo de negocios, porque su prioridad se inclina por adelantar sus estudios y realizar otras actividades diferentes a trabajar.

También se pudo evidenciar que no se encuentran personas mayores de 45 años, porque son considerados de muy avanzada edad, no cuentan con la capacidad para realizar los oficios que les exige la administración y atención de una tienda, y en su mayoría son casados, ya que es muy común que tanto el dueño como su esposa se dedican a atender el negocio e incluso también lo hacen sus hijos, lo que ha demostrado la investigación, situación representada en cerca de 79\% de las tiendas.

\section{La tienda de barrio}

Las tiendas de barrio suelen ser pequeñas empresas familiares, cuyo local ocupa parte del domicilio de los propietarios, enfocada en la venta al por menor de productos de consumo masivo, como lácteos, hortalizas, verduras, productos de aseo, cocina, confitería, cigarrería y licores. En algunos casos pueden incluir una pequeña sección de panadería o de papelería.

El comercio tradicional es independiente, no asociado ni vinculado a ningún tipo de establecimiento; de tamaño pequeño, por el número de puntos de venta con que cuenta, la cifra de empleados y la dimensión del establecimiento; no disponen de tecnología avanzada por el régimen de venta utilizado, el equipamiento disponible, la formación de su personal y la personería jurídica más usada es persona natural. 
La estructura de tienda encontrada en la investigación se destaca el crecimiento de tiendas misceláneas que incluyen servicios y productos adicionales de droguería, variedades, fruterías, máquinas paga monedas, carnicerías y servicio telefónico.

En las tiendas de barrio de Cartagena se hace gran parte de la vida social del barrio. En torno a una cerveza los vecinos departen y juegan a las cartas o al dominó, se organizan partidos de softbol o de béisbol, se ponen en común los últimos acontecimientos, los bailes y allí se reúne la gente a compartir su cotidianidad.

\section{Tiendas vs. supermercados}

Para la década de 1990, los supermercados se enfrentaron al desembarco de los hipermercados y las grandes cadenas. Luego, se enfrentaron a la recesión y después a la crisis pos devaluación que afectó directamente el poder adquisitivo de la población y provocó una caída abrupta en el consumo.

En estudios realizados por A.C. Nielsen en 1998 cuando el consumo en supermercados crecía al $7 \%$ y el de la tienda caía, y entonces se le decretó la muerte al canal tradicional. Sin embargo, estaba apenas en cuidados intensivos y si bien recayó, como los otros canales con la crisis económica de finales de la década de 1990, ha resaltado su papel. Según un estudio de Homescan y A.C. Nielsen, para el segundo semestre de 2002 el crecimiento de las ventas de los supermercados era de $43 \%$, en comparación con las tiendas que crecían $42 \%$.

Según Londoño (2008b, p. 49), en la actualidad en Colombia hay cerca de 450.000 tenderos, de los cuales 4,3 personas dependen de ellos y de esta actividad, lo que equivale aproximadamente a que dos millones de colombianos están involucrados o viven de esta actividad.

Para el segundo semestre de 2003 los porcentajes de crecimiento con respecto a las ventas se habían igualado a $42 \%$. Un año después, las tiendas se iban por encima de los supermercados y crecían $44 \%$, en comparación con sus gigantes competidores, que crecían solo 42\%. El año 2005 fue de prosperidad para los tenderos, con un crecimiento de $45 \%$ y ventas de 16,5 billones de pesos, que superaba ampliamente el $41 \%$ de crecimiento de los supermercados, con ventas de 14,2 billones de pesos (Londoño, 2007).

A pesar de que hace siete años los estadistas vaticinaban que el sector tradicional desaparecería por el ingreso de las grandes superficies de mercado, la tienda de barrio se niega a desaparecer. Las cifras así lo demuestran (Gráfico 4).

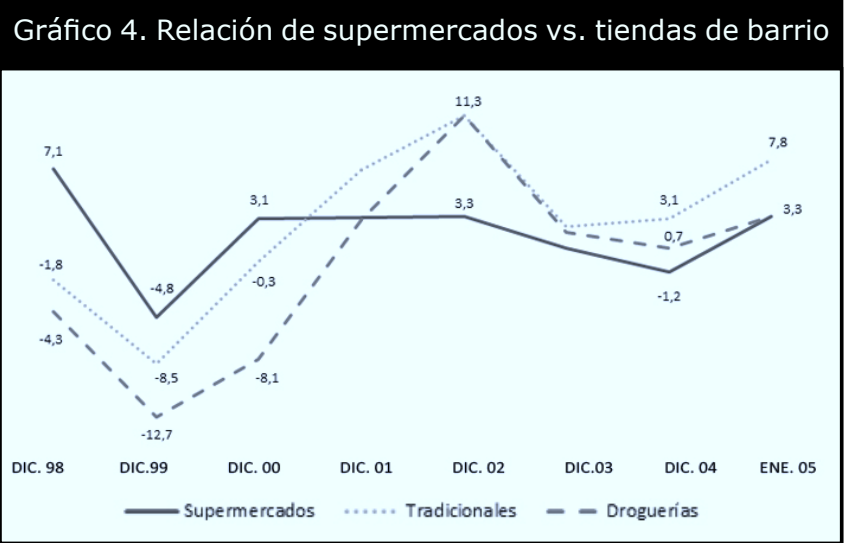

Fuente: Revista Dinero, 2006.

.Las tiendas, de acuerdo con A.C. Nielsen movieron en 2005 , cerca de 16,5 billones de pesos, un crecimiento de $22 \%$ en los últimos dos años, un poco más que los supermercados que llegaron a 14,2 billones. Dos razones pesan a la hora de analizar el crecimiento: la primera, que el precio en el canal tradicional aumentó $2 \%$, mientras que en supermercados creció $2,8 \%$. Y, la segunda, que hoy el canal tradicional tiene un mayor surtido: hay un crecimiento del $4,5 \%$ en la cantidad de productos que tiene disponible el tendero (antes si entraba un producto, tenía que salir otro). Este mayor surtido no solo está acompañado de más cantidad de marcas sino también con presentaciones que implican un menor gasto para el cliente, Por su parte, los supermercados se han recuperado, con un crecimiento en ventas del $16 \%$ y de número de almacenes de un 18\% en los últimos dos años (Revista Dinero, 2003).

\section{Surtido de las tiendas}

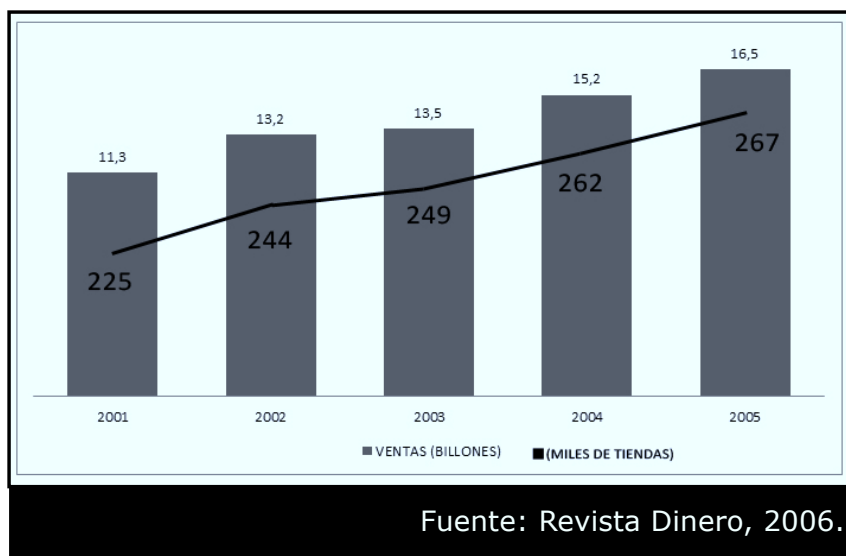


El sector comercio en cuanto a las grandes superficies tiene que enfrentar otro cambio estructural para volver a recuperar los niveles de venta consolidados antes de la crisis: por un lado, los consumidores poscrisis, y por otro, el crecimiento del comercio tradicional. El sector se está enfrentando a un consumidor más racional al que no se le vende solo por promoción o impulso, sino que valora tanto la cercanía como el precio y realiza compras más frecuentes y de menor monto.

Hoy en día las tiendas de barrio poseen el 65\% del mercado de bienes de consumo masivo en Colombia. Considerada hace poco el enemigo chico de las grandes cadenas comerciales, han probado ser el gran ganador en la distribución de productos de consumo popular en el país (Revista Dinero, 2004). Las tiendas no solo sobrevivieron a la enorme inversión que significó la primera ola de expansión de los hipermercados, que empezó en 1990 con la entrada del Éxito en Bogotá, siguió en 1995 con la llegada de Makro y en 1998 con la de Carrefour, pero al contrario de lo que muchos habían anunciado en los años 1990, estas crecieron.

Por otro lado, las ventas de los hipermercados crecieron en muebles, electrodomésticos y artículos de ferretería -cerca del 18\% en 2004, según datos de A.C. Nielsen-, pero no en productos de consumo masivo, esto desvela a los hipermercaderistas por una razón contundente: un estudio de la Strategy Research Corporation muestra que las personas de menores ingresos que se surten en las tiendas, y que corresponde al 90,1\% de la población colombiana, tienen el $44 \%$ del poder de compra y adquieren el 58\% de los productos masivos del país (Revista Dinero, 2004) .

Aunque los hipermercados, supermercados y almacenes de cadena han crecido en los últimos años esto no ha reducido el número de tiendas; por el contrario, se han incrementado debido a algunos de los factores ya mencionados y, además, porque en Colombia una parte importante de la población merca a diario por no tener ingresos suficientes para hacerlo en forma semanal o quincenal, lo que se suma a que las facilidades que les brindan los tenderos a sus clientes, no se las pueden ofrecer los supermercados (crédito, envío de los productos a su casa, venta al menudeo, entre otros aspectos), razón por la cual los llamados canales tradicionales o tiendas han cobrado una mayor importancia, ya que es el punto de compra diaria del consumidor y, en general, el punto de reposición de productos de los colombianos. De acuerdo con estudios sobre el perfil del consumidor (Aguilera, Bernal y Quintero, 2006, p. 58), el canal tradicional tiene el 43\% del mercado (año 2002), a pesar de la expansión que han tenido las grandes cadenas de supermercados y la presencia de pequeños autoservicios.

Si bien el comercio alrededor de los nuevos supermercados e hipermercados se afectó, las tiendas siguen jugando un papel muy importante entre los canales de distribución. Una suma de factores económicos, culturales y comerciales ha impedido que la tienda pierda su lugar en la economía colombiana (gráfico 5).

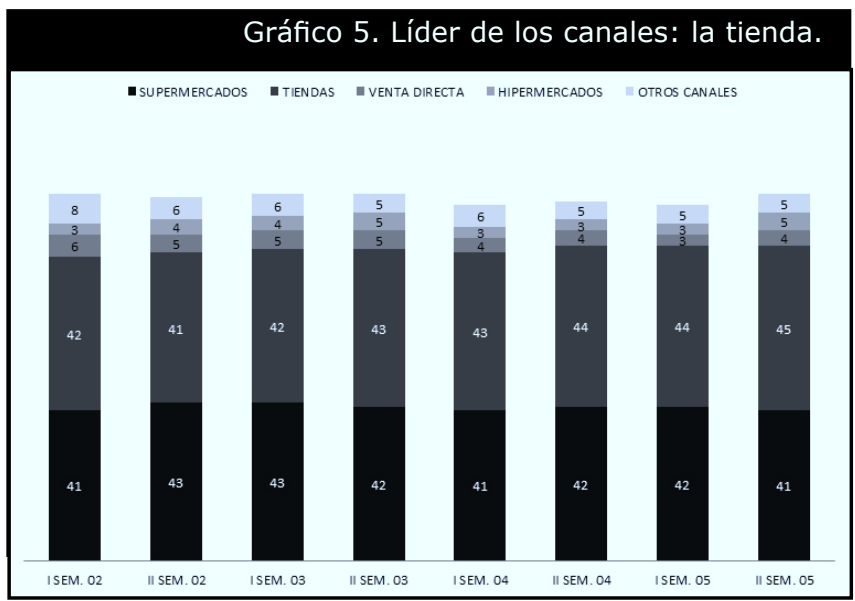

Fuente: Dinero, 2006.

\section{Conclusiones}

- La tienda en los barrios es de gran trascendencia para la gente, porque con frecuencia no hay cerca grandes supermercados, y hacer las compras en la tienda se ahorran gastos de transporte y otras incomodidades. Además la estrategia comercial del menudeo, constituye una opción accesible e importante para los vecinos del barrio.

- Este tipo de negocios populares son básicos porque el tendero le colabora al cliente con el menudeo y se acomoda al presupuesto de ellos, y además cuando la gente necesita adquirir un producto, busca siempre el sitio más cercano, y ese lugar casi siempre es una tienda.

- Entre los servicios que brinda la tienda esta el crédito, "fiado o credicartón", constituyendo uno de los servicios más antiguos: no requiere fiadores, ni cédulas, pero sí la constancia y confianza de quien lo solicita. Aunque actualmente las tiendas se han visto en la necesidad de involucrar más artículos y 
prestar más servicios como llamadas por celular, fotocopiadora, papelería y atención a domicilio, este último no solo se ofrece en los estratos altos, sino también se está empezando a poner en práctica en las tiendas de los barrios populares, con el fin de atraer más clientes.

Por los aspectos mencionados se destaca la importancia de las tiendas en su labor de responder a las necesidades diarias del cliente. Los consumidores las prefieren por la posibilidad de fiar, de tener domicilios gratis y hasta de contar con productos en tamaños personales que se ajustan a su ingreso. Otra de las ventajas de las tiendas, si se compara con los grandes almacenes de cadena, es que las personas compran productos por porciones o lo que necesiten en el momento.

De esta manera las tiendas tratan de acomodarse a sus clientes de acuerdo con sus necesidades o capacidad adquisitiva y de compra. Este menudeo siempre ha existido, pero la diferencia está en que ahora no solo se ve en los barrios de estratos medios y bajos sino también en los barrios de estratos altos.

Para las comunidades de Cartagena, las tiendas de barrio son hoy en día un motor para el desarrollo económico y siguen siendo el canal preferido para los consumidores a la hora de comprar productos de la canasta familiar (El Universal, 2006). Y es por ello que en los últimos años las tiendas de barrio han crecido y los consumidores pueden encontrar además de víveres, también productos perecederos como jamón, verduras, frutas y hasta artículos de cacharrería.

Tan impresionante ha sido el crecimiento de las tiendas en los últimos siete años, que en 2005 en el ámbito nacional, vendieron mucho más en conjunto de lo que vendieron los hipermercados, lo que evidencia que siguen siendo las preferidas del consumidor y de más fácil acceso, brindando muchos beneficios, observándose que a medida en que hay nuevos supermercados las tiendas siguen creciendo en forma paralela, y no han sido afectadas sino que se ha estimulado la economía de este sector (El Universal, 2006).

La tienda no solo provee al consumidor de la compra diaria, sino que tiene ventajas que los supermercados no pueden igualar: como la proximidad respecto a sus clientes actuales y potenciales. La tienda además tiene a su favor otras características que le confieren un lugar de privilegio como distribuidor de productos entre los estratos medios y bajos de una ciudad como Cartagena, en donde la pobreza alcanza niveles cercanos al 60\%, como son la posibilidad de compra por pequeños volúmenes, o la de obtener un crédito sin ningún tipo de formalidad institucional o soporte financiero, dirigido a permitir la adquisición de bienes básicos de consumo durante el lapso de tiempo necesario para reunir el dinero y pagarlos. De acuerdo con la investigación aquellos tenderos que ofrecen como valor agregado el crédito a sus clientes, lo administran a corto plazo: el mínimo es de una semana y el máximo de un mes.

El horario de atención al público en promedio va desde las 6 de la mañana a las 10 de la noche, es decir, el tendero brinda a sus clientes diecisiete y hasta dieciocho horas continuas de servicio los fines de semana; la amplitud de este horario permite la facilidad de acceso en el momento de comprar en cualquier hora del día, inclusive en horas picos o de almuerzo y cena, todo por satisfacer su necesidad de compra y tener al cliente a gusto con la atención del tendero para garantizar su fidelidad. Al establecer rangos de atención se observa que el 37\% se ubica exactamente en el horario mencionado, un $27 \%$ ofrece una hora adicional de servicio y $22 \%$ reduce el tiempo de atención en una hora jornada nocturna, solo un $14 \%$ trabaja en horario de 7 de la mañana a 11 de la noche.

Hablar del éxito de las tiendas de barrio a pesar de la expansión de los supermercados no es algo contradictorio, más bien quiere decir que ese tipo de condiciones han contribuido a que este sector considerado en conjunto se muestre fuerte e incluso ha prosperado en medio de épocas de crisis y desaceleración de la economía. En ese sentido las tiendas de barrio han triunfado aún en contra de los vaticinios de expertos.

La caracterización de la tienda de barrio en Cartagena se definió con base en los resultados obtenidos en la investigación realizada, la cual permitió establecer aspectos claves entre los que se pueden destacar:

En el desarrollo de la investigación se evidenció que los papeles desempeñados por las personas que atienden la tienda son: los propietarios de este tipo de establecimientos comerciales, los cuales representan un gran porcentaje con una participación del 35\%, le siguen los vendedores con 34\% y los administradores de tiendas con $31 \%$.

Los principales clientes con los que cuenta la tienda son los vecinos, como lo demuestra la investigación realizada en los distintos barrios de Cartagena, en donde 
los tenderos manifestaron que 63\% de sus clientes son sus vecinos, y $37 \%$ personas de barrios vecinos. Cabe anotar que la tienda al estar ubicada en barrios residenciales le permite acceder más a las personas que viven en estos barrios, además estos clientes van a la tienda por el ahorro de tiempo y para evitar la ida al supermercado, dado que se va a comprar en pequeñas cantidades y con un gasto mínimo de dinero.

Referente a los tipos de clientes que más compran en las tiendas de barrio de la ciudad, se tiene en primer lugar, se encuentran las amas de casa con 50\% de participación, siguiendo en el mismo orden los niños con un significativo porcentaje de participación (25\%).

Los retos de esta investigación preliminar consisten en destacar la importancia de las tiendas de barrio en el desarrollo económico de la ciudad, en especial la de los estratos menos favorecidos, así como posibilitar con las entidades municipales y gubernamentales el apoyo para estos tipos de microempresarios, de tal forma que reconozcan su importancia y a la vez se les preste apoyo en especial en los temas administrativos para que estos desarrollos permitan el bienestar de la población.

\section{Anexo A. Productos para tenderos}

\begin{tabular}{|l|l|l|}
\hline \multicolumn{2}{|c|}{ Producto } & \multicolumn{1}{c|}{$\begin{array}{c}\text { Acción del } \\
\text { tendero }\end{array}$} \\
\hline Aceite & $\begin{array}{l}\text { Acción de la } \\
\text { industria } \\
\text { o vasos usando o } \\
\text { no dispensador }\end{array}$ & $\begin{array}{l}\text { Presentaciones } \\
\text { de 250 cc }\end{array}$ \\
\hline $\begin{array}{l}\text { Aguardiente y } \\
\text { ron }\end{array}$ & $\begin{array}{l}\text { Venta por tragos } \\
\text { (copita) }\end{array}$ & $\begin{array}{l}\text { Presentación de } \\
175 \text { cc }\end{array}$ \\
\hline Arroz & $\begin{array}{l}1 / 2 \text { ó 1/4 de libra } \\
\text { vendida a granel } \\
\text { o fraccionando al } \\
\text { bolsa de 1 libra }\end{array}$ & $\begin{array}{l}\text { Presentaciones } \\
\text { de } 1 / 2 \text { libra }\end{array}$ \\
\hline Azúcar & $\begin{array}{l}\text { 1/2 ó 1/4 de libra } \\
\text { vendida a granel } \\
\text { o fraccionando al } \\
\text { bolsa de 1 libra }\end{array}$ & $\begin{array}{l}\text { Presentaciones } \\
\text { de } 1 / 2 \text { libra }\end{array}$ \\
\hline
\end{tabular}

\begin{tabular}{|c|c|c|}
\hline Producto & $\begin{array}{l}\text { Acción del } \\
\text { tendero }\end{array}$ & $\begin{array}{l}\text { Acción de la } \\
\text { industria }\end{array}$ \\
\hline $\begin{array}{l}\text { Chocolate ins- } \\
\text { tantáneo }\end{array}$ & $\begin{array}{l}\text { Venta por cucha- } \\
\text { radas }\end{array}$ & $\begin{array}{l}\text { Papeletas de } 200 \\
100,50 \text { gramos }\end{array}$ \\
\hline Blanqueador & Venta por copas & Cojines de $100 \mathrm{co}$ \\
\hline Café molido & Venta por pesaje & $\begin{array}{l}\text { Presentaciones } \\
\text { de papeleteas de } \\
50 \text { gramos }\end{array}$ \\
\hline $\begin{array}{l}\text { Café instantá- } \\
\text { neo }\end{array}$ & $\begin{array}{l}\text { Venta por cucha- } \\
\text { radas }\end{array}$ & $\begin{array}{l}\text { Papeletas de } 8 \text { y } \\
10 \text { gramos }\end{array}$ \\
\hline Café con leche & & $\begin{array}{l}\text { Papeletas de } 25 \\
\text { gramos }\end{array}$ \\
\hline Cereal en polvo & $\begin{array}{l}\text { Venta por cucha- } \\
\text { radas }\end{array}$ & $\begin{array}{l}\text { Papeleta de } 25 \\
\text { gramos }\end{array}$ \\
\hline $\begin{array}{l}\text { Cereal en ho- } \\
\text { juelas }\end{array}$ & $\begin{array}{l}\text { Venta por cucha- } \\
\text { radas }\end{array}$ & $\begin{array}{l}\text { Cajitas o sobres } \\
\text { de } 35 \text { gramos }\end{array}$ \\
\hline Champú & Venta por tapas & $\begin{array}{l}\text { Cojín de } 10 \text { mili- } \\
\text { gramos }\end{array}$ \\
\hline Cigarrillos & Venta por unidad & $\begin{array}{l}\text { Paquete de } 3 \text { y } 5 \\
\text { cigarrilos }\end{array}$ \\
\hline Creolina & $\begin{array}{l}\text { Venta por tapas o } \\
\text { copitas }\end{array}$ & $\begin{array}{l}\text { Bolsita de } 4 \\
\text { onzas }\end{array}$ \\
\hline Crema dental & $\begin{array}{l}\text { Venta por centí- } \\
\text { metros }\end{array}$ & $\begin{array}{l}\text { Tubo de } 38 \text { gra- } \\
\text { mos y papeleta } \\
\text { de } 10 \text { miligramos }\end{array}$ \\
\hline
\end{tabular}




\begin{tabular}{|c|c|c|c|c|c|}
\hline Producto & $\begin{array}{l}\text { Acción del } \\
\text { tendero }\end{array}$ & $\begin{array}{l}\text { Acción de la } \\
\text { industria }\end{array}$ & Producto & $\begin{array}{l}\text { Acción del } \\
\text { tendero }\end{array}$ & $\begin{array}{l}\text { Acción de la } \\
\text { industria }\end{array}$ \\
\hline $\begin{array}{l}\text { Concentrados } \\
\text { de pollo y } \\
\text { carne }\end{array}$ & $\begin{array}{l}\text { Venta de } 1 / 2 \text { o } 1 / 4 \\
\text { de cubito me- } \\
\text { diante fracciona- } \\
\text { miento. }\end{array}$ & $\begin{array}{l}\text { Cubitos más } \\
\text { pequeños empa- } \\
\text { cados de forma } \\
\text { individual }\end{array}$ & Leche & $\begin{array}{l}500 \text { ó } 250 \text { centí- } \\
\text { metros cúbicos } \\
\text { Fraccionando una } \\
\text { bolsa de un litro }\end{array}$ & $\begin{array}{l}\text { Producción de } \\
\text { presentaciones } \\
\text { de } 500 \text { y } 350 \text { y } \\
8 \text { onzas centíme- } \\
\text { tros cúbicos }\end{array}$ \\
\hline Desinfectantes & $\begin{array}{l}\text { Venta por tapas y } \\
\text { copitas }\end{array}$ & $\begin{array}{l}\text { Potecitos de } 125 \\
\text { cc }\end{array}$ & Leche en polvo & $\begin{array}{l}\text { Venta por cucha- } \\
\text { radas }\end{array}$ & Sobre de 8 onzas \\
\hline Desodorante & & $\begin{array}{l}\text { Sobre de } 10 \text { mili- } \\
\text { gramos }\end{array}$ & $\begin{array}{l}\text { Mantequilla y } \\
\text { margarina }\end{array}$ & $\begin{array}{l}1 / 2 \text { o } 1 / 3 \text { de una } \\
\text { barrita de } 125 \\
\text { gramos }\end{array}$ & $\begin{array}{l}\text { Barritas de } 50 \\
\text { gramos. }\end{array}$ \\
\hline Detergente & $\begin{array}{l}\text { Venta por vasos o } \\
\text { por peso }\end{array}$ & $\begin{array}{l}\text { Cojines de } 150 \\
\text { gramos }\end{array}$ & \multirow[t]{3}{*}{ Mayone } & \multirow{2}{*}{$\begin{array}{l}\text { Venta por cucha- } \\
\text { radas. }\end{array}$} & \multirow[t]{2}{*}{ Sobres de $50 \mathrm{cc}$} \\
\hline \multirow{2}{*}{$\begin{array}{l}\text { Enjuague para } \\
\text { el cabello }\end{array}$} & & \multirow{2}{*}{$\begin{array}{l}\text { Cojín de } 10 \text { mili- } \\
\text { gramos }\end{array}$} & & & \\
\hline & & & & & \\
\hline $\begin{array}{l}\text { Enjuague para } \\
\text { la ropa }\end{array}$ & $\begin{array}{l}\text { Venta por tapas o } \\
\text { copitas }\end{array}$ & $\begin{array}{l}\text { Potecitos de } 200 \\
\text { cc y cojines de } \\
100 \text { cc }\end{array}$ & Mortadela & Venta por tajadas & $\begin{array}{l}\text { Paquete de } 100 \\
\text { gramos }\end{array}$ \\
\hline \multirow{2}{*}{$\begin{array}{l}\text { Galletas de } \\
\text { soda }\end{array}$} & \multirow{2}{*}{$\begin{array}{l}\text { Venta por unida- } \\
\text { des }\end{array}$} & \multirow{2}{*}{$\begin{array}{l}\text { Taco con } 2 \text { mita- } \\
\text { des empacadas } \\
\text { individualmente } \\
\text { Taco con tres } \\
\text { paqueticos } \\
\text { Taco con cuatro } \\
\text { paqueticos } \\
\text { Unidad con } 3 \\
\text { galletas }\end{array}$} & Panela & & \\
\hline & & & $\begin{array}{l}\text { Pañuelos des- } \\
\text { echables }\end{array}$ & $\begin{array}{l}\text { Venta por unida- } \\
\text { des }\end{array}$ & $\begin{array}{l}\text { Paquetico de } 3 \text { a } \\
10 \text { pañuelos }\end{array}$ \\
\hline $\begin{array}{l}\text { Jabón para el } \\
\text { baño }\end{array}$ & Fracción de barra & $\begin{array}{l}\text { Barras de } 90 \\
\text { gramos }\end{array}$ & $\begin{array}{l}\text { Protectores } \\
\text { diarios }\end{array}$ & Venta por unidad & $\begin{array}{l}\text { Protectores en } \\
\text { empaque indivi- } \\
\text { dual }\end{array}$ \\
\hline
\end{tabular}




\begin{tabular}{|c|c|c|}
\hline Producto & $\begin{array}{l}\text { Acción del } \\
\text { tendero }\end{array}$ & $\begin{array}{l}\text { Acción de la } \\
\text { industria }\end{array}$ \\
\hline $\begin{array}{l}\text { Refresco ins- } \\
\text { tantáneo }\end{array}$ & & $\begin{array}{l}\text { Producción de } \\
\text { presentaciones } \\
\text { en papeletas de } \\
50 \text { gramos }\end{array}$ \\
\hline Salchichas & $\begin{array}{l}\text { Venta por unidad } \\
\text { o fracción }\end{array}$ & $\begin{array}{l}\text { Presentaciones } \\
\text { de varios tama- } \\
\text { ños, empacados } \\
\text { de forma indivi- } \\
\text { dual }\end{array}$ \\
\hline Salsa de tomate & Venta por vasos & Cojín de 50 cc \\
\hline $\begin{array}{l}\text { Toallas sanita- } \\
\text { rias }\end{array}$ & $\begin{array}{l}\text { Venta por unidad } \\
\text { desempacando la } \\
\text { bolsa de } 10,20 \text { o } \\
30 \text { unidades }\end{array}$ & $\begin{array}{l}\text { Toallas empa- } \\
\text { cadas de forma } \\
\text { individual }\end{array}$ \\
\hline Vinagre & $\begin{array}{l}\text { Una o más tapas } \\
\text { (medida con la } \\
\text { tapa de la botella) } \\
\text { o vasos }\end{array}$ & $\begin{array}{l}\text { Producción y } \\
\text { presentación } \\
\text { de vinagre en } \\
\text { cojines }\end{array}$ \\
\hline Esencias & $\begin{array}{l}\text { Venta por tapita } \\
\text { o vasito }\end{array}$ & Sobres \\
\hline Yogurt & & $\begin{array}{l}\text { Presentaciones } \\
\text { de } 8 \text { onzas }\end{array}$ \\
\hline
\end{tabular}

Fuente: tomado de los trabajos de, campo realizado por los estudiantes de Administración de Empresas de la Universidad de Cartagena en la asignatura de investigación de mercados. La tienda de barrio en Colombia, un canal importante en la distribución de productos de gran consumo. Encuentro de profesores investigadores en comercialización Educa-AL Universidad Nacional de Santa Fe. Santa Fe Argentina. Octubre 2005.

\section{Bibliografía}

1. A. Nielsen. (2001). Comportamiento del comercio detallista en Latinoamérica. X Conferencia Panamericana de comercio detallista (presentación en ppt.2006).

2. Aguilera, D.; Bernal, M.; Quintero, P. (2006): El perfil del consumidor. Edición 251, abril 14: 58.
3. Alvarado, Saida; Enríquez, Josefina. (2000). Hábitos y motivos de compra de alimentos de las familias de estratos 5 y 6 de Cartagena. Cartagena: Universidad de Cartagena.

4. Álvarez, F.; Miriam y Almeida, Sigrid. (1991). Nivel de consumo de una familia tipo en Cartagena. Cartagena: Universidad de Cartagena.

5. Areiza V., Carlos Alberto. (2001). Presente y futuro del canal tradicional en la ciudad de Cali. Estudios Gerenciales. Cali.

6. Berné Manero, Carmen; Pedraja Iglesias, Marta; Rivera Torres, Pilar. (1997). El análisis de la productividad del comercio minorista a través de la medición directa del nivel de satisfacción del cliente. Revista Europea de Dirección y Economía de la Empresa, 6 (4): 11 -24.

7. Botero, M.; Jaraba, B. (2005). Las tiendas de barrio en el suroccidente de Colombia. Obtenida el 26 de mayo de 2010 de http://inpsicon.com/lo-quehacemos/revista-el-consumidor/articulos/523-mar\%C3\%ADa-mercedes-botero-y-bruno-jarababarrios.html

8. Casares Ripol, Javier; Rebollo Arévalo, Alfonso. (1996 y 2000). Distribución Comercial. Madrid: Editorial Cívitas.

9. Chirouze, Yves. 1982. Le Choix des Canaux de Distribution. París : Dunod Entreprise: 5.

10. Departamento Nacional de Estadística (DANE). S.f. Colombia: ventas del comercio 1996-2006.

11. Departamento Nacional de Estadística (DANE). S.f. Colombia: ventas de los grandes supermercados según grupos de mercancías 1997-2006.

12. Departamento Nacional de Estadística (DANE). S.f. Colombia: personal ocupado en los grandes almacenes e hipermercados, según tipo de contratación 1996-2006.

13. Departamento Nacional de Estadística (DANE). S.f. Colombia: producto interno bruto 1996-2006.

14. Departamento Nacional de Estadística (DANE). S.f. Colombia: producto interno bruto de comercio 19962006.

15. Déjame masticarlo. (2004, 23 de julio). Revista Dinero. (210), 51-52. 
16. Espinosa, Aarón; Rueda, Fabio. (2006). Simposio de las desigualdades regionales. Pobreza y vulnerabilidad en Cartagena.

17. Fernández Rodríguez, Roberto. (1998). Mercados minoristas tradicionales de Madrid. Documentos de Trabajo. Facultad de Ciencias Económicas y Empresariales.

18. Federación Nacional de Comerciantes (Fenalco). 2008. Concepto de tienda de barrio.

19. Hasty, Ron; y Reardon, James. (1998). Gerencia de ventas al detal. Ed. Mc Graw Hill, 11, 16-19, 33.

20. Herrera, Camilo. (2006). Dinámica del consumo en Colombia. Raddar, abril.

21. Kotler, Philiph; y Armstrong, Gary. 1996. Principios of Marketing ( $6^{a}$ edición). Prentice Hall.

22. Kotler, Philiph; y Armstrong, Gary. (2003). Fundamentos de Marketing, México: Pearson Educación de México, SA de CV.

23. La tienda no se rinde. (2003, 24 de junio). Revista Dinero. (184).

24. Las tiendas de barrio ayudan al consumidor cartagenero. (2006). Periódico El Universal.

25. Lambin, Jean Jacques (1995): Marketing estratégica (3a edición). Madrid: Mcgraw-Hill, 413-415, 419, 420.

26. Laudo, David; y Dolla, Alber. (1995). Comportamiento del consumidor: conceptos y aplicaciones (4 ed). México: Mc. Graw Hill.

27. Lewinson M., Dale. (1999). Ventas al detalle (6a edición). México: Ed. Prentince Hall, 6,7, 45, 52, 69, $638,642,643,651,654$.

28. Londoño, E. (2008). Evolución del comercio minorista de productos de gran consumo en Colombia. España: Universidad de Alcalá.

29. Muñoz Alvis, Andrés; Peralta Coneo, Reynaldo. (2006). Tiendas de barrio colombianas. Investigación en psicología del consumidor. Barranquilla.

30. O’ Byrne Cuéllar, Natalia; Calp, Gláucia. (2008). Informe especial - Sector retail Colombia de Corporativos Colombia. DCR Duff y Phelps de Colombia. Sociedad Calificadora de Calores: 4.
31. Pérgolis, J.; y Moreno, D. (1998). El barrio, el alma inquieta de la ciudad. En: Ciudad y hábitat (5).

32. Pride, William; y Ferrel, OC. (1997). Marketing conceptos y estrategias (9a edición). Ed. McGraw Hill: $438,464$.

33. Porto A., Sandra; Herrera, B.; Dorelvis. (2002). El consumidor en Cartagena de Indias: hábitos, determinantes y características. Universidad de Cartagena.

34. Santesmases M., Miguel. (1996): Términos de marketing - Diccionario - Bases de datos. Madrid: Ediciones Pirámide.

35. Santesmases M., Miguel. (1999). Marketing conceptos y estrategias (4a edición). Madrid: Ediciones Pirámide.

36. Stanton, Wiliam; Etzel J., Michael; y Walter, Bruce J. (1999). Fundamentos de marketing (undécima edición). Ed. Mc Graw Hill.

37. Vásquez, Bibiana; Bueso Carla; Novoa, Carlos; Perea Segnini, Juan C.; Ramela, Susana. S.f. Desarrollo empresarial de tenderos de Cartagena. Documento del Banco Interamericano de Desarrollo Fondo Multinacional de Inversiones.

38. Yudes, P. (1990). Organización informal, sector popular. En: Boletín Cultural y Bibliográfico, XXVII (23). Disponible en: http://www.banrep.gov.co/blaa virtual/boleti5/bol23/organiz.htm 